\section{Energy: how to decide}

Planning inquiries, such as the Windscale Inquiry in which the UK debated whether to allow expansion of a nuclear reprocessing plant, are not the only means for debating the UK's technological future. Here Professor David Pearce, Ms Lynne Edwards, and Mr Geoff Bueret discuss the options

NuClear power is the technology which could probably meet the 'energy gap' between projected demand and supply most quickly; but it raises issues that a concerned society must debate: the threat to civil liberties, the proliferation of nuclear weapons, the risk of accident and the extraordinary problem of storing radioactive waste for longer than any single civilisation has yet survived.

Science, we are told, must be for the people; so decisions about new technologies must be accountable to the public. But the public has limited technical understanding; and the institutions which exist to resove public issues are the products of an age when few were concerned with technical problems. In the UK, the standard response has been to rely on extra-parliamentary institutions such as Royal Commissions, major Inquiry Commissions, the institution of the Ombudsman, administrative tribunals, and public inquiries.

But is this an efficient context for deciding on an energy future?

\section{The Windscale Inquiry}

Typically, local planning inquiries in the UK consider local issues, although national concerns may be involved: any motorway, for example, is part of a national network so that the local decision affects the network plan. But by and large, the nation's needs never dominated local inquiries--until the inquiry at Whitehaven between June and November 1977 into the proposal to reprocess nuclear waste fuels at Windscale. The Secretary of State for the Environment issued national terms of reference for that inquiry. They spoke of "the safety of the public" and vaguely of "other aspects of the national interest" as well as local issues of employment and amenity.

It is arguable that the national issues raised at the Windscale Inquiry should have been debated elsewhere. Clearly, they should be debated in Parliament; yet by placing the debate in the context of a local inquiry, the Secretary of State appeared inadvertently to obstruct this. Planning inquiry law would be contravened if in the course of a parliamentary debate 'fresh evidence'

The authors are researching into the implications of the Windscale Inquiry for future energy decisions in the UK. They wish to acknowledge a grant from the

Energy Panel of the Social Science

Research Council. was introduced which affected the Minister's own internal assessment, so rendering a proper parliamentary discussion impossible. But the minister has now found an awkward way round this obstacle. There will be a debate.

By including national issues in the terms of reference of the Windscale Inquiry a precedent has been set. do not exist for local inquiries. In future, therefore, unless the law is changed, any local inquiry could be opened up to debate national issues. This could mean an inquiry every time a nuclear site is chosen or even existing sites expanded.

Ignoring present commissioned nuclear power stations, the Department of Energy's (DEN) 'central' energy forecasts imply about $135 \mathrm{GW}$ installed nuclear capacity in the UK in the year 2025. If future sites are assumed to be 4 or $5 \mathrm{GW}$ in size something like 30 sites would be required by 2025 , or one new site less than every two years. Larger sites of, say, $8 \mathrm{GW}$ would reduce the site acquisition rate, as would any further potential for building on existing sites. There is also a $15 \mathrm{GW}$ 'policy gap' in the central forecasts for the year 2000 but there would be every prospect of this being met by an existing thermal reactor system. To many people, the DEN's forecasts seem too high; but the point here is to illustrate the implications for decision-making if they are correct.

The prospect of a biennial nuclear debate is particularly daunting because of two factors. If the urgency of energy decision-making is accepted, then the prospect of a filibuster against Strictly speaking, 'terms of reference' nuclear development along the lines of the one that has developed in the United States becomes real. Such a filibuster might be attractive to antinuclear groups if it were not likely to generate widespread apathy about the issues through continuous repetition. Keeping the local inquiry as a possible context for energy debates should give no satisfaction to either the pro- or anti-nuclear camps.

\section{How should an energy future be decided?}

The choice of decision-making process for energy futures will affect the nature of that future. If the 'policy gap' can be met by some combination of combined heat and power schemes, solar installations, conservation, heat pumps and perhaps wind and wave power it seems unlikely that the existing ad hoc procedures for public participation need be altered. In particular, the local inquiry must stay to deal with what the local people want.

On the other hand, a coaldominated scenario, however, would raise 'national' concerns, since the prospect of doubling coal output by 2025 would involve significant developments on the scale of the Selby and Belvoir coalfields. But nuclear dominated future demands the greatest departure from existing procedures: the belief that there are issues of a profound ethical nature is sufficient to justify this dichotomy.

If the local inquiry is not the most efficient context for making such decisions - although it must remain the proper context for a siting decision. how are the views of pressure groups and the public to be heard? Pressure groups and the public are not necessarily one and the same. The former tend to be genuinely concerned, but professional, elites with no direct or obvious mass support. Some believe they have this support, but most would admit that their role is an educative and persuasive one.

\section{Sorry, for copyright reasons some images on this page may not be available online}


The public, on the other hand, has limited access to information about the issues involved in the nuclear debate. The answer may lie in information campaigns of the kind that have taken place in Austria, Denmark and Sweden where government funds are used to produce neutral documents conveying the facts as they might seem to a disinterested party, although the problems of defining a 'neutral fact' cannot be underestimated. Pressure groups may also be funded to produce their own literature and campaigns given that nuclear authorities already fund their own less explicit campaigns and their own defence at public inquiries. The alternative is to leave the

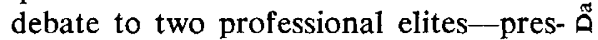
sure groups and the establishment. This will happen anyway and the extra dimension of public participation may not materialise. Yet the public should at least have the opportunity of expressing its concern.

Once sufficiently informed, how are the people to convey their views to the elected? The normal processes for relay between constituent and parliamentary member seem redundant if no political party is to take up the cause. At the moment, energy futures do not divide along party lines. For extraparliamentary debates the pressure groups are not on equal terms with their opponents since their funds are limited even if their expertise is often commendably high. If the debate is to be fair it would seem right to fund their activities on the basis of 'open government'. The dilemma arises in trying to define who constitutes a pressure group and how accountable they are to be in their use of funds. Failure to supply funds could be construed as a strategic mistake since a pressure group has no better excuse for resort to 'civil disobedience' campaigns than that all other channels have been closed to it. Yet if funds were supplied the pressure groups would be required to accept the outcome of any debate and the pro-nuclear camp is quick to point out that some pressure groups may never take 'no' for an answer. Equally, pro-nuclear pressure will not disappear if the debate goes against the establishment policy.

Another problem is whether any government information programme, on the lines of the Austrian, Swedish, and Danish models, should include a preliminary assessment of the project in question, perhaps taking the form of a cost-benefit study or an environmental impact statement? Apart from the problems of determining who will undertake such work, is any purpose served by such documents beyond what is achieved by the submissions of the various parties to the debate? The quality of submissions would vary

\section{Sorry, for copyright reasons some images on this page may not be available online}

Mr. Justice Parker investigates at the
Windscale works in Cumbria

widely, although aid to objecting parties could help. Nor do we escape the problem of putting the issues before the public if the impact statement or cost-benefit study is comprehensible only to the professionals. Yet there are real dangers in reducing the issues to the 'common sense' level, for it may be that some issues are just not reducible to common sense with the sacrifice of accuracy.

All this leaves the fundamental question still unanswered. Accepting the need for some extra-parliamentary debate involving pressure groups and at least a campaign to inform the public, what is the proper structure and form of that debate?

\section{Issues not objectors}

Basic principles of organisation seem clear. The debate should proceed by issue and not by some sequence of objectors, frequently overlapping and repeating views, as at Windscale. The adversarial context has its role if only because it permits cross examination and the extraction of information from parties to the debate, information that otherwise might not emerge. But whether or not the context needs to be a legal one is another matter. There is much to be said for the view that lawyers 'intervene' between experts, losing arguments for want of knowledge. Equally, if the adversarial context is a requirement then their training is partly fitted to the context. The quasi-judicial framework fails in other respects since it again favours the professional and discriminates against those who may not articulate their views in the same way.

The form of the institution responsible for the debate is also dependent on a policy decision. Is any decision about the nuclear future a once-and-for-all decision, or one that we can expect to see debated again and again? The technological argument seems to favour the second option since a commitment to one fast reactor should not imply a necessary commitment to the second. Nonetheless, one can appreciate the fears of those who see the sequence as being irreversible in practice, a kind of nuclear future by stealth.

Opposition to nuclear power is not likely to go away because one national debate decides against it, any more than the reverse is the case. The institutional context should therefore be semi-permanent, capable of being reconstituted when the debate is renewed. No existing standing authority would seem to meet any of the requirements laid down for equal access by people of opposing views-as an example the Energy Commission contains no representative of pressure groups outside the fuel industries themselves, their trade unions and a few individuals.

A standing commission would seem to favour the Royal Commission format. Yet a Royal Commission has no formal link with Parliament: it can only advise and there is no requirement on the Minister to make any decision on its recommendations, whereas he is (theoretically, anyway) with the local inquiry. The Commission in question must therefore have a recommendatory power which obliges the relevant Minister to deliberate on its recommendations. Further, there should be no obstacle between the recommendation and parliamentary debate before a decision is made. Otherwise we shall witness the growth of a decision-making framework which by-passes Parliament. An Inquiry Commission empowered to sit whenever the debate seems necessary will be costly. It may, however, be the only form of institution that meets the requirements for efficiency in an imperfect world.

Arguably, all this concern comes too late. North Sea oil will be very shortlived and the energy demands of the 1990 s must be met by technologies about which we must decide now. A decision-making procedure that postpones decisions could be costly in terms of employment and income. Equally, it would be a naive industry that did not plan for such delays and perhaps there is time for a wholesale debate. Probably, there is no alternative. Failure to establish the requisite institution now leaves us with the ad hoc procedures we already have and we have shown that they can readily generate the same problem of delay.

Failure to allow any debate through either existing or new institutions will merely lead some pressure groups to adopt less democratic forms of action that might threaten the very basis of decision-making itself. 